\title{
Explaining the different ownership structure in Korea and the U.S. trucking industries
}

\author{
Wonchang Jang ${ }^{*}$ and Ilsoon Shin ${ }^{* *}$
}

\begin{abstract}
One of the distinctive features in Korea and the U.S. trucking industries is the huge difference in the share of owner-operators. While it is around 10 15 percent in the U.S., 80 90\% of drivers operate their own truck in Korea. Different from historical explanations of previous researches, this paper deals with this feature theoretically. We examine what brings the difference in asset ownership structures between the Korean and the U.S. trucking industries. Using an analytic framework, we investigate the determinants of truck ownership and the changes in ownership patterns. The model introduces several parameters related to productivities of drivers' efforts and contractibility to affect drivers' decision, and values of these parameters in both countries are discussed qualitatively and found to be consistent with the aforementioned characteristics.
\end{abstract}

Keywords: trucking industry, owner-operator, for-hire carrier, asset ownership, market structure.

\section{Introduction}

One of the distinctive features in Korea and the U.S. trucking industries is the huge difference in the share of owner-operators. While it is around 10 15 percent in the U.S., 80 90\% of trucks are driven by owner-operators in Korea. The abnormally large portion of owner-operator in Korea has often been mentioned as the primary obstacle hindering further advancement of the domestic trucking industry. Since the owner-operators are generally fragmented and small-scale businessmen, they face 
fierce competition for hauls. This leads to the unusual overgrowth of agents, namely dispatchers, who act as intermediators between shippers and owner-operators. As of 2004, the number of the dispatchers $(13,448)$ outnumbered that of the for-hire carriers $(7,934)$ in Korea. The result is that the adoption of the information technology has been slow or even resisted, which further keeps the industry being in a fragmented state.

Previous studies present several historical reasons for the status quo of widespread existence of owner-operators. First, the status quo is ascribed to the fact that the trucking business had been a licensed business domestically, and licensees are more inclined to do business with owneroperators rather to purchase trucks and employ drivers. Second, the license system was transformed into a registry system in 1999. As a result, a massive entry of owner operators into the trucking industry took place. Third, the situation was aggravated in the aftermath of 1997 financial crisis, which forced out many laid-off workers into self-supporting jobs, such as an owner-operator of truck. $^{1}$

In this paper, we employ an approach which differs from previously raised explanations for the difference in asset ownership structures between the Korean and the U.S. trucking industries. Using an analytic framework that draws heavily on the asset ownership theories of Grossman and Hart (1986) and Hart and Moore (1990), we investigate what determines truck ownership and how ownership patterns change as aspects of the business environment changes.

It should be noted that market-clearing mechanisms in the trucking industry have been different from that in textbook economic models. Participants do not simply observe prices and decide how much capacity to sell or buy, because capacity and demands are highly differentiated in terms of time, location, and equipment characteristics. Instead, capacity and demand are matched in a highly decentralized manner in which buyers, sellers, and intermediaries engage in costly searches. Given these situations, truck ownership can be understood as the institutional responses within the broad market to these features of the trucking industry.

We propose that an important benefit of owner-operator is that the owner drives his truck in ways that better preserves its value as compared with driving for a fleet owner. However, owneroperator scheme leads to inefficiencies associated with bargaining over truck utilization because the dispatcher who arranges trucking schedule no longer has critical control over the truck. When dispatchers are negligent in matching the 'backhauls' on return trips, owner-operators might bid fair to engage in inefficient rent-seeking behavior.

The rest of the paper is organized as follows. The next section describes the general features and the different ownership structures in the U.S. and Korea trucking industry. In Section 3, we set up the model with asset ownership and analyze it under various types of truck ownership. Section 4 discusses the model implications derived from Section 3. Section 5 presents conclusions and qualifications.

\footnotetext{
${ }^{1}$ The government reverted to license system again in 2004 again to reduce the entry into the market. More detailed information on the government policy can be found in Lee (2008).
} 


\section{Economics and ownership features of trucking industry}

\subsection{General features}

The production process in trucking is simple. It starts with cargo being loaded onto a truck. A driver operates the truck to its destination, where the cargo is unloaded. The output of the production process is the movement of cargo. Demanders of trucking services are called 'shippers' and suppliers are 'carriers'. Carriers consist of 'for-hire' trucking firms and 'private fleets' (trucking divisions of firms that are not trucking specialists). It is common for a carrier's drivers to be a mix of 'owner-operators' who are not owners but instead are hired to drive for trucking companies.

In general, costs per unit of output in trucking fall with capacity utilization. The average (or per-unit) cost of moving cargo on a truck increases less than proportionately with the weight of the cargo; and truck owners bear opportunity costs when trucks are idle. Improving capacity utilization is the key to attain higher productivity in trucking industry. Capacity utilization is high when trucks haul a series of full loads, each of which starts close to and soon after the previous one is finished.

Attaining high levels of capacity utilization is not easy since the demand for truck capacity is generally lumpy and location and time-specific. If shippers have consistent demands to transport enough loads of cargo between two points, utilization can be improved by dedicating trucks to a specific shipper and route. In most cases, however, individual shipments are one-way trip and often do not fill the carrying capacity of a truck. When demands are unidirectional, search should be directed at identifying shippers with demands that would fill the truck for the return trip, so-called 'backhaul'. When individual shipments are too small to fill a truck, search takes the form of identifying other shippers with similar demands.

Thus, for a given aggregate demand, capacity utilization depends largely on how well individuals can identify and agglomerate complementary demands onto individual trucks. Higher quality matches increase capacity utilization by keeping trucks on the road and loaded more, and therefore raise truck drivers' productivity. Capacity utilization in the trucking industry depends crucially on how efficiently supply (trucks) and demand (hauls) are matched. Trucks and hauls are matched in a highly decentralized manner in which shippers, carriers, and third-party intermediaries search for good matches.

Operationally, the people most directly involved in matching capacity to demand are 'dispatchers/brokers'. Dispatchers assign trucks and drivers to hauls. Dispatchers who manage shippers' private fleets primarily assign trucks to their internal customer's hauls. Those who manage for-hire carriers' fleets assign trucks to external customer's hauls. Sometimes dispatchers actively search for good backhauls to improve capacity utilization by contacting shippers either directly or through brokers. ${ }^{3}$

\footnotetext{
'`Private fleet' is the same meaning as 'in-house', which is more common terminology in Korea.

${ }^{3}$ There is subtle industrial organizational difference in US and Korea. In Korea, the dispatchers are usually brokers to the owner-operators, and they never consider the schedule of back-hauls of owner-operators, which is one-time contract.
} 
Dispatchers work in a highly dynamic environment. Assignments and schedules are not set far in advance because it is hard to forecast the arrival of demands and the availability of trucks. In practice, dispatchers assign trucks and drivers to a series of hauls at the beginning of the day on a provisional schedule. They then update schedules throughout the day, rearranging assignments in response to unexpected delays and new orders (some of which they may have actively solicited to fill the capacity).

Information is a critical input to dispatchers' decisions. In particular, knowing where trucks are and how full their trailers are helps dispatchers to allocate trucks across existing orders and market spare capacity more efficiently. Possessing this information, they can provide customers better information about arrival times. Information processing and communication capabilities are important, in turn, to dispatchers for making a good decision by, for example, redirecting drivers.

In sum, the market clearing mechanism in trucking differs from that in textbook economic models. Market clearing in the trucking industry does not involve participants simply observing prices and deciding how much capacity to sell to or buy from the market. The unique, localized characteristics of the trucking industry mean that centralized markets have traditionally been uncommon in trucking. Capacity and demands are highly differentiated in terms of time, location, and equipment characteristics, and capacity and demand are matched in a highly decentralized manner in which buyers, sellers, and intermediaries engage in costly search.

Meanwhile, two types of incentive problems exist in the relationship between drivers and carriers. One involves how the truck is driven. It has traditionally been difficult to verify how drivers operate trucks, since they are operated remotely. Other than knowing whether the truck and driver arrived on time at their destination, the carrier has had little information about a truck once it is on the road. Wear and tear on the truck is minimized when drivers drive at a steady and moderate speed, but drivers may prefer to drive fast because it allows them to take longer breaks, visit friends, etc., and still arrive on time. Drivers' scope for this type of non-optimal driving occurs particularly for longer hauls because there are more opportunities to make up time.

The other incentive problem results from the incomplete nature of contracting over the use of the truck. Agreements between carriers and drivers generally cover multiple periods and multiple hauls, but they generally do not clarify in advance which hauls drivers will complete because flexibility in scheduling is critical to capacity utilization. Conflicts between carriers and drivers arise because drivers' preferences vary with hauls, but obligations to hauls are not specified in agreements. For instance, hauls into congested or dangerous areas are less desirable to drivers, but indifferent to carriers. Carriers negotiate with drivers to induce them to accept undesirable hauls, particularly when drivers are far from their base and carriers have no other drivers in the area. This negotiation usually involves a combination of moral suasion, promises to assign drivers desirable hauls in the future, and sometimes pecuniary compensation.

One incentive instrument for addressing these conflicts is asset ownership. The benefit of an owner-operator is clear. Drivers who own their truck have an incentive to drive carefully in consideration of the truck's residual value. If the driver does not own the truck, however, he is likely to commit reckless driving that damages the vehicle.

The incentives induced by asset ownership with respect to negotiation over the backhaul are 
more complex. If the carrier owns the truck, it can mandate that the truck be used for profitable backhauls. However, if the driver owns the truck, the carrier tries less for arrangement of timecritical pickup even though it might be highly profitable. The owner-operator may engage in costly search for alternative hauls in order to strengthen his bargaining position with the dispatcher and threaten not to carry a particular backhaul lined up by the dispatcher.

\subsection{Different ownership structures in the U.S. and Korea}

Though asset ownership approach is a common way of addressing incentive problems in the trucking industry, the current ownership structures are quite different in the U.S. and Korea.

Figure 1 shows the U.S. owner-operator shares in 1987, 1992, and 2002, ranging from 10 to 15 percent. ${ }^{4}$ The overall share fluctuated during this period, decreasing from 14.6 percent to 10.1 percent between 1987 and 1992, then rising back to 14.8 percent in 2002. Though there is no detailed survey on trucks in Korea, we can guess the share from Chung and Lim (2006), and Lee (2008). They estimated that the owner-operator in Korea is about 80 90 percent in 2002. Taken together, we find a huge difference in owner-operator share between U.S. and Korea.

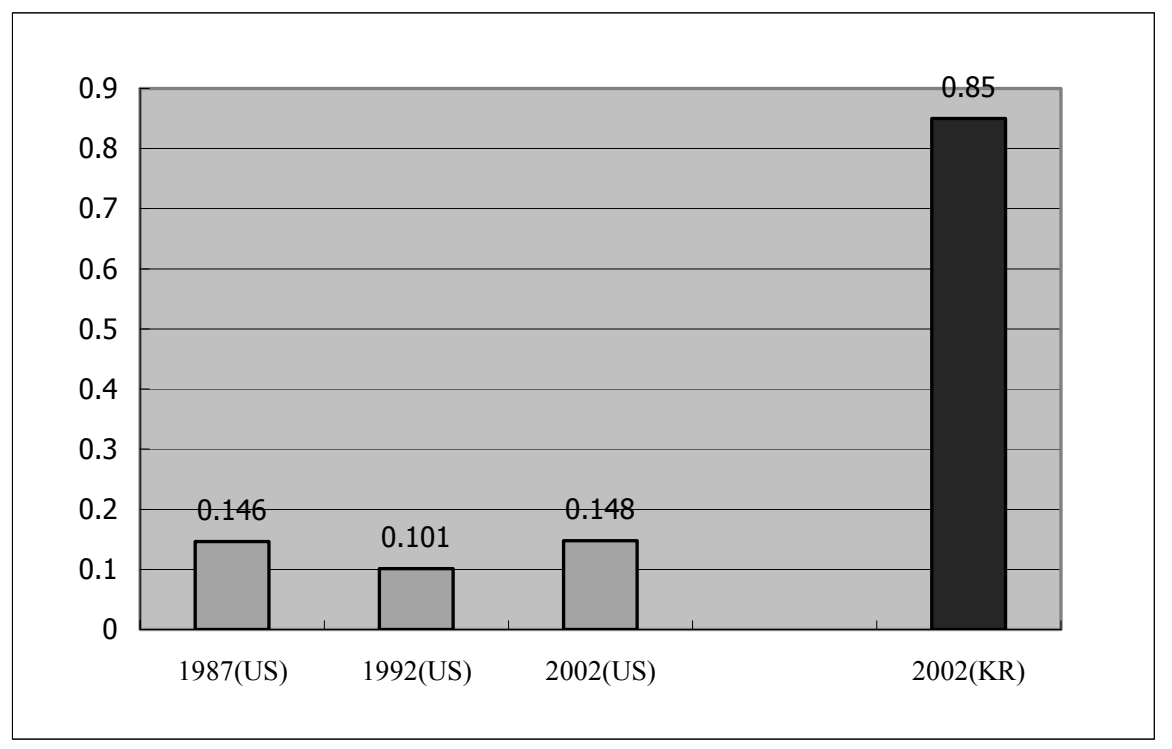

Fig 1. Share of owner-operator in U.S. and Korea

\footnotetext{
${ }^{4}$ The U.S. data are from the Vehicle Inventory and Use Survey (VIUS). The VIUS is a mail-out survey of trucks taken by the U.S. Census Bureau. The Bureau sends forms to a random sample of truck owners. These forms ask questions about individual trucks' characteristics. Truck owners report the truck's type (pick-up, van, tractor-trailer, etc.), make, model, and many other characteristics. The survey also asks whether the truck was driven by an owneroperator or a company driver. This paper uses only observations of tractor-trailer and excludes all other types of vehicles as in Hubbard $(2000,2003)$.
} 
Although beyond the scope of this paper, shippers' make-or-buy decision is another margin that addresses the incentive problems in trucking industry. Shippers' make-or-buy decision corresponds to whether they use a truck from either internal fleets or external fleets for a haul. Private and for-hire carriage are distinguished by truck ownership. In private carriage, shippers own trucks and they can alter trucks' schedules unless existing agreements are violated. In for-hire carriage, shippers do not own trucks and they must negotiate change in truck schedules with carriers.

The negotiation in for-hire carriage is accompanied with a sort of transaction costs. Both parties have an incentive to improve their bargaining position and thus engage in rent-seeking behavior. Under for-hire carriage, truck utilization also is improved by for-hire carrier's efforts to obtain market information and search for complementary hauls.

It is also noteworthy that U.S. and Korea show a significant difference in the share of private fleets. While about half of trucks operate within private fleets in the U.S., 90 percent of trucks belong to private fleets in Korea (see Figure 2). These differences could reflect the relative underdevelopment of for-hire carriers in Korea. In the next section, we investigate the causes of these differences between U.S. and Korea.

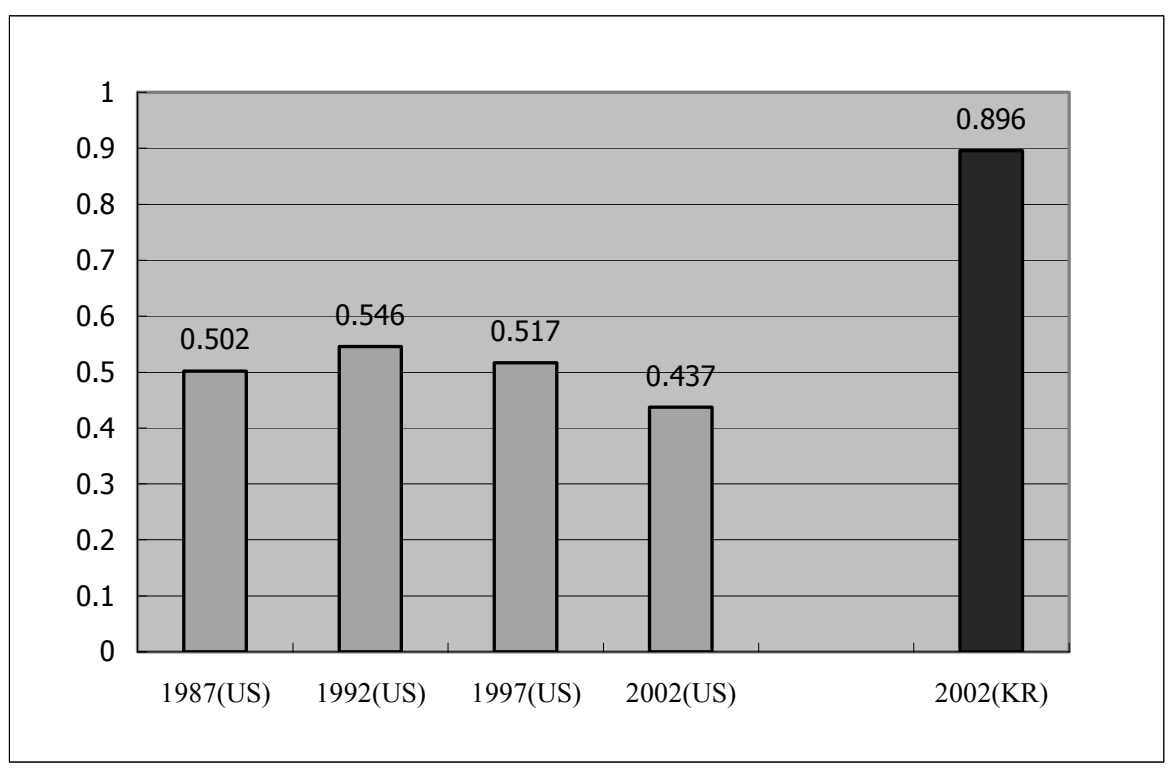

Fig 2. Share of private fleets in U.S. and Korea 


\section{The model}

\subsection{Setup}

In the model, we investigate what determines whether drivers own the trucks they operate, and how ownership patterns change as some environment factors change. The analytic framework draws heavily on the asset ownership theories of Grossman and Hart (1986) and Hart and Moore (1990). In doing this, we try to differentiate our work from the previous researches that depend heavily on the historical anecdotes for the explanation of the emergence of owner operators.

We start with an initial situation where there exist many drivers who own their trucks. Their options are twofold; first, to remain as an owner-operator, or second, to be part of a for-hire carriage firm. ${ }^{5}$ For a driver to be a part of for-hire carrier, he should share the ownership with the carrier (we denote this as 'carrier ownership' hereafter) and follow the major decision made by the carrier. The owner-operator (we denote this as 'driver ownership' hereafter) has the ownership of the truck, but has to depend on the dispatcher owing to the decentralized nature of the market. To focus on the decision of drivers, we assume that there are many carriers and dispatchers, and they behave in a perfectly competitive market.

Suppose that the payoff of a driver if he chooses to be a part of a for-hire carrier, denoted by , $V_{c}$ and the payoff of a driver if he remains as an owner-operator, denoted by, $V_{o}$ are:

$$
\begin{aligned}
& V_{c}=A+\alpha_{1} e_{1} \\
& V_{o}=\alpha_{1} e_{1}+\alpha_{2} e_{2}
\end{aligned}
$$

The meanings of these equations are as follows. The relative payoff of being a part of a carrier instead of an owner-operator increases with the value of $A$. Among other things, the actual value of $A$ would depend on the extent of economies of scale and the size of the market, because carriers should have truck operation and maintenance facilities and need parking space, which involves partly the feature of fixed inputs. Obviously the extent of economies of scale would depend on the size of the market.

A driver can increase his payoff with two different actions (or efforts) $e_{1}$ and $e_{2}$. Here, $e_{1}$ is the meaningful effort regardless of the truck ownership he chooses, while $e_{2}$ applies only to owneroperators. Among other things, $e_{1}$ could include actions that enhance the driver's productivity in general. In the context of trucking industry, expending more effort and resources in vehicle maintenance and careful driving is one example. Drivers also perform non-driving service activities, such as helping load and unload the truck and sort and store the cargo, which can also be considered another example. Hereafter we refer $e_{1}$ as 'common effort'.

\footnotetext{
${ }^{5}$ Note that it is not double bargaining situation, which means a driver bargain with several agents. In that case, outside options will be endogenous, and the model becomes unnecessarily complicated.
} 
Meanwhile, $e_{2}$ consists of actions that increase a driver's value only if he owns the truck. Among other things, $e_{2}$ includes activity such as finding backhauls by drivers themselves. It is valuable given driver ownership because such effort raises their capacity utilization, thus productivity. However, it does not increase a driver's value given carrier ownership because it is better for driver to follow carrier's backhaul placement and instead focus on other activities.

Hereafter we refer $e_{2}$ as 'specific effort'. Note that $e_{2}$ effort is productive conditional on the truck ownership, but opportunistic conditional on the carrier ownership. Here, $a_{1}$ and $a_{2}$ are parameters specifying the marginal products of these efforts.

Furthermore we assume that $e_{1}$ and $e_{2}$ are non-contractible. ${ }^{6}$ Non-contractible efforts mean that contracts on the efforts cannot be verifiable to outsiders, thus cannot be written and enforced. If one party's efforts have a greater impact on the gains from trade, then the party should be given stronger incentives for those efforts. In this case, the concerned agents choose their efforts simultaneously since efforts cannot be specified in the contract. For contractible efforts, however, stronger incentives can be written into the contract and they are determined in the contract, leading to an optimal outcome. Hence, determining the efficient pattern of asset ownership becomes important.

Next, a driver incurs the cost related to the efforts according to the equation (3).

$$
C=\frac{1}{2}\left(e_{1}\right)^{2}+\frac{1}{2}\left(e_{2}\right)^{2} \text {. }
$$

The timing of the model is three-stage. In the first stage, a driver decides whether he remains as an owner-operator or would be a part of a carrier. In the second stage, he decides his efforts $e_{1}$ and $e_{2}$ to maximize his own payoff, conditional on the ownership decisions made in the first stage. In the final stage, driver and carrier (or dispatcher if he chooses to be a owner-operator) observe $V_{c}$ and $V_{o}$, and should split the returns.

With the timing and non-contractible efforts we assumed, driver and carrier (or dispatcher) should negotiate over the surplus in the third stage. However, since it is quite impossible to split the returns perfectly with non-contractible efforts, we assume the outcome of bargaining in the third stage is the Nash bargaining solution (Grossman and Hart, 1986; Hart and Moore, 1990; Hart, 1995). When two players negotiate, the Nash bargaining solution is to split the extra surplus equally (Clemons and Kleindorfer, 1992; Han et al., 2004).

Since the extra surplus is additional payoff compared to the value of outside option when the cooperative relation is annulled, we normalize carrier's (or dispatcher's) outside option to zero, regardless of truck ownership. The value of a driver's outside option is assumed to be $W$ (his wage in another job) in case of carrier ownership, implying that the driver should leave the industry when the cooperative relation with a carrier is annulled. We also assume that the driver does not need to consider his outside options in case of driver ownership, implying that he can remain as an owneroperator, and can be in touch with dispatchers as long as he wants.

\footnotetext{
${ }^{6}$ This assumption on non-contactable efforts is mitigated in the later section.
} 


\subsection{Efforts and payoffs under various asset ownerships}

Below we will see the level of efforts and payoffs under different structures of asset ownership. First, let us see the case of the carrier ownership. In this case, the driver chooses $e_{1}$ and $e_{2}$ to maximize his net payoffs in the following equation.

$$
\frac{V_{c}-W}{2}+W-C=\frac{V_{c}+W}{2}-C=\frac{1}{2}\left(A+\alpha_{1} e_{1}+W\right)-\frac{1}{2}\left(e_{1}\right)^{2}-\frac{1}{2}\left(e_{2}\right)^{2}
$$

The solutions of this problem are $e_{1}=\frac{\alpha_{1}}{2}$ and $e_{2}=0$. The solutions mean that the driver chooses less than optimal common effort level and the optimal specific effort level. Note that the optimal efforts levels are $e_{1}=\alpha_{1}$ and $e_{2}=0 .^{7}$ When the driver chooses the non-contractible efforts ex ante and takes into account the possibility of contract annulment, the value of outside option is $W$. We can see that the common effort is valuable only when a contract is retained, thus choosing the less than optimal common effort level is his rational decision since he takes account of the possibility of contract annulment, in which the common effort is wasteful. On the other hand, the specific effort is not valuable regardless of contract retention or annulment. Thus he chooses to expend no specific effort, which is also the optimal solution under carrier ownership. Using these effort levels, net payoff outcome equals $A+\frac{3}{8} \alpha_{1}^{2}$.

Second, let us see the case of the driver ownership. In this case, the driver chooses $e_{1}$ and $e_{2}$ to maximize the following.

$$
\frac{V_{o}-V_{o}}{2}+V_{o}-C=V_{o}-C=\alpha_{1} e_{1}+\alpha_{2} e_{2}-\frac{1}{2}\left(e_{1}\right)^{2}-\frac{1}{2}\left(e_{2}\right)^{2} .
$$

Actually the problem is the same as all efforts are contractible. The solutions of this problem are $e_{1}=\alpha_{1}$ and $e_{2}=\alpha_{2}$. The marginal products of the efforts are equal to the marginal costs, thus the solution is optimal. The resulting net payoff outcome is $\frac{\alpha_{1}{ }^{2}+\alpha_{2}{ }^{2}}{2}$. Note that the driver involves any bargaining since his can remain an owner-operator as long as he wants. In this situation he chooses the privately optimal effort levels.

The efforts levels and resulting net payoffs in different asset ownership structures are summarized in Table 1.

\footnotetext{
${ }^{7}$ Here, optimal level means effort level a driver chooses when all the efforts would be contractible. If all the efforts would be contractible, then the driver maximizes $V_{c}-C$ The solutions are $e_{1}=a_{1}$ and $e_{2}=0$. Note also that they satisfy the usual condition that marginal productivity of effort equals marginal cost.

${ }^{8}$ The net payoff outcome is derived from $V_{c}-C$ inserting efforts levels. Thus it could be interpreted as the ex post net payoff of a driver when the relationship with a carrier is retained.
} 
Table 1

Effort and payoff under various asset ownerships

\begin{tabular}{c|c}
\hline Carrier Ownership & Driver Ownership \\
\hline \hline Efforts: $e_{1}=0.5 \alpha_{1}, e_{2}=0$ & Efforts: $e_{1}=\alpha_{1}, e_{2}=\alpha_{2}$ \\
Net payoff: $A+\frac{3}{8} \alpha_{1}{ }^{2}$ & Net payoff: $\frac{\alpha_{1}{ }^{2}+\alpha_{2}{ }^{2}}{2}$ \\
\hline
\end{tabular}

Looking at the solutions, we can see that they conform to the usual intuition. It is completely reasonable that the common efforts are more expended in driver ownership since he will put more resources and efforts in vehicle maintenance, safe driving, non-driving services if he owns the truck. In contrary, the driver will put more specific efforts only when it is profitable to do so. Since specific effort, such as finding backhauls by driver himself, is meaningless in carrier ownership, it is not expended at all.

\subsection{Decision on the ownership}

Here, we deal with the actual decision of drivers on the ownership structure. With the net payoffs derived in Table 1, we can compare the difference of truck ownership on a driver's payoff. That is, if the following equation is satisfied, the net payoff of carrier ownership is larger than that of driver ownership.

$$
A>\bar{A} \equiv \frac{1}{8} \alpha_{1}^{2}+\frac{1}{2} \alpha_{2}^{2}
$$

Thus the carrier ownership will be chosen instead of driver ownership. If the inequality sign is reversed, driver ownership will be chosen. Here $\bar{A}$ is a cutoff point, above which carrier ownership is chosen by a driver. Figure 3 shows the regions of each truck ownerships, dividing both net payoffs in equation (6) by $a_{2}$ and subtract driver ownership net payoff from carrier ownership net payoff. Then equation (6) can be rewritten as follows.

$$
\frac{A}{\alpha_{2}{ }^{2}}>\frac{1}{8}\left(\frac{\alpha_{1}^{2}}{\alpha_{2}^{2}}\right)+\frac{1}{2}
$$




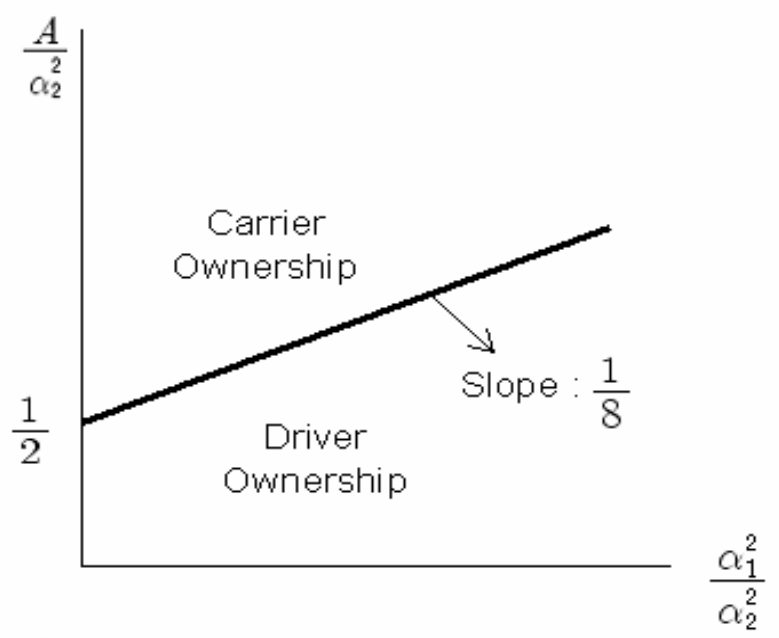

Fig 3. Decision on the Ownership

Thus, the resulting ownership depends on the specific values of parameters $A, a_{1}$ and $a_{2}$. Note that these parameters are the relative contribution to payoff of carrier ownership, the marginal productivity of common effort and the specific effort, respectively. It is obvious to show that

$$
\frac{\partial \bar{A}}{\partial \alpha_{1}}>0, \frac{\partial \bar{A}}{\partial \alpha_{2}}>0 .
$$

These conditions mean that if $a_{1}$ increases (or $a_{2}$ increases), there is more chance for the driver to choose driver ownership. When the marginal product of common effort $\left(a_{1}\right)$ is large enough, the driver will be placed far from the origin to the right part of the graph, meaning that the driver ownership is likely to be occurred. If the driver's common effort is quite contributory to the payoff, it is better for him to own the truck since the common efforts are expended more heavily in driver ownership as discussed before. On the other hand, when the marginal product of specific effort $\left(a_{2}\right)$ is large enough, the driver will be placed near the origin the graph, meaning that the driver ownership is likely to be occurred. If the driver's specific effort is quite contributory to the payoff, it is obvious for him to own the truck.

Also it is obvious that the increase in $A$ leads to the rise of possibility of choosing carrier ownership away from driver ownership. With other parameters being constant, a driver will be placed up in the graph with the increase in $A$, which means the increased possibility of choosing carrier ownership. 


\subsection{Extension into contractible efforts}

Above we assume that driver and carrier negotiate over the ownership, but they cannot contract over the common and specific efforts. That is, the efforts are non-contractible. In this section we introduce partly contractible efforts. That is, as the proportions of $t_{1}$ and $t_{2}$ among efforts $e_{1}$ and $e_{2}$ are still non-contractible, the remaining proportions of $1-t_{1}$ and $1-t_{2}$ are contractible. With the value of $t_{1}=t_{2}=1$, the analysis is completely the same as the above section.

With this change, the equations (1) (3) should be modified as follows.

$$
\begin{aligned}
& V_{c}=A+\alpha_{1}\left\{\left(1-t_{1}\right) e_{1}^{C}+t_{1} e_{1}^{N}\right\} \\
& V_{o}=\alpha_{1}\left\{\left(1-t_{1}\right) e_{1}^{C}+t_{1} e_{1}^{N}\right\}+\alpha_{2}\left\{\left(1-t_{2}\right) e_{2}^{C}+t_{2} e_{2}^{N}\right\} \\
& C=\frac{1}{2}\left(1-t_{1}\right)\left(e_{1}^{C}\right)^{2}+\frac{1}{2} t_{1}\left(e_{1}^{C}\right)^{2}+\frac{1}{2}\left(1-t_{2}\right)\left(e_{2}^{N}\right)^{2}+\frac{1}{2} t_{2}\left(e_{2}^{N}\right)^{2}
\end{aligned}
$$

where $e_{1}{ }^{C}, e_{2}{ }^{C}$ and $e_{1}^{N}, e_{2}^{N}$ denote the contractible efforts and non-contractible efforts among $e_{1}, e_{2}$.

The process for solving for the non-contractible efforts are similar as above, while the contractible efforts are determined to maximize $V_{C}-C$ and $V_{o}-C$ respectively, since in this case, efforts can be specified ex ante in the contract, and the integrated payoffs are those of drivers due to assumption of perfect carrier market. The solutions in case of carrier ownership are $\left(e_{1}{ }^{C}, e_{2}{ }^{C}\right)=$ $\left(a_{1}, 0\right)$ since the specific effort is no longer meaningful. Likewise, the solutions in case of driver ownership are $\left(e_{1}{ }^{C}, e_{2}{ }^{C}\right)=\left(a_{1}, a_{2}\right)$. The results are summarized in Table 2 .

Table 2

Effort and payoff under various asset ownerships (contractible efforts)

\begin{tabular}{c|c}
\hline Carrier Ownership & Driver Ownership \\
\hline \hline Efforts: $e_{1}{ }^{N}=0.5 \alpha_{1}, e_{2}{ }^{N}=0$ & Efforts: $e_{1}{ }^{N}=\alpha_{1}, e_{2}{ }^{N}=\alpha_{2}$ \\
$e_{1}{ }^{C}=\alpha_{1}, \quad e_{2}{ }^{C}=0$ & $e_{1}{ }^{C}=\alpha_{1}, e_{2}{ }^{C}=\alpha_{2}$ \\
Net Payoff: $A+\frac{\left(4-t_{1}\right)}{8} \alpha_{1}{ }^{2}$ & Net Payoff: $\frac{\alpha_{1}{ }^{2}+\alpha_{2}{ }^{2}}{2}$ \\
\hline
\end{tabular}

The level of contractible efforts and non-contractible efforts are different in carrier ownership. Note that the driver chooses the same level of non-contractible efforts as before. Now it is possible 
to contract some portion of efforts, the contract should make the useless effort minimize and the productive effort maximize. Thus the level of the contractible effort is set to be at the optimal level.

With the net payoffs derived above, we can compare the different truck ownership on a driver's payoff. If the following equation is satisfied, the net payoff of carrier ownership is larger than that of driver ownership.

$$
A>\bar{A} \equiv \frac{t_{1}}{8} \alpha_{1}^{2}+\frac{1}{2} \alpha_{2}^{2}
$$

It is obvious to show that

$$
\frac{\partial \bar{A}}{\partial t_{1}}>0, \frac{\partial \bar{A}}{\partial t_{2}}=0 .
$$

Equation (13) means that increasing common effort contractibility (decrease in $t_{1}$ ) reduces the chance for the driver to choose owner-operator, while specific effort contractibility has no effects on the result.

Figure 4 shows the effect of decreasing $t_{1}$, the fraction of common effort that is noncontractible. Decreasing $t_{1}$ shifts the slope of borders of ownership to the lower direction, which means larger possibility of choosing carrier ownership.

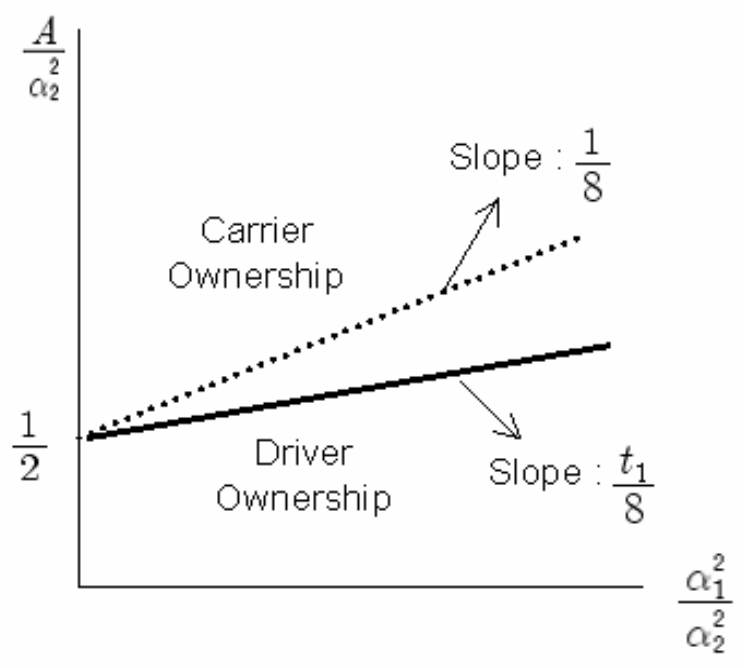

Fig 4. Increase contractibility in common effort 
This can be explained as follows. Increasing common effort contractibility indicates that there is more chance to choose the optimal level of the common effort. Since the common effort is set to be the less than optimal level in carrier ownership, there is extra effect of increase in contractibility. On the other hand, since the specific effort is already expended the optimal level in driver ownership, increase in contractibility has no extra effect. Thus the payoff in the carrier ownership increased relative to driver ownership when contractibility in common effort is increased.

The situation is different in specific effort. Increasing specific effort contractibility also indicates that there is more chance to choose the optimal level of the specific effort. The specific effort is set to the optimal level both in carrier and driver ownership, thus the increase in contractibility is helpless. Thus increasing contractibility in specific effort has no extra effect on both payoffs.

\section{Discussions}

In this section, we explain the aforementioned different characteristic of Korea and U.S. trucking market with the prediction of the above model. When we apply the above model to the Korean and U.S. trucking market, the difference in the share of owner-operators would be generated from several factors, that is, difference in values of parameters $A, a_{1}, a_{2}, t_{1}$. In other words, Korean trucking industry may inherently have smaller $A$, and/or larger $a_{1}, a_{2}$, and/or larger $t_{1}$. Below we will address qualitatively that those parameters are changed consistently with the actual phenomena of the market.

At the outset, it should be noted that economic theorists have frequently cited trucks as prototypical nonspecific assets, thus the occurrence of owner-operators is consequent. Williamson (1985, p. 54) states that "durable but mobile assets such as general purpose trucks ... [are] redeployable," and hence should not be subject to the contracting hazards that specific investments incur. Klein et al. (1978, p. 244) contend that, unlike installed printing equipment, trucks are "generally easily movable and not very specific." Similarly, Milgrom and Roberts (1992, pp. 249, 311) argue that, given the pairing of relatively easily measured delivery performance and difficultto-measure vehicle care, long-haul drivers should own their trucks. Given the generic nature of trucks, - mobility, simplicity of operation, ease of redeployment - all these theorists predicts that owner-operators will be a dominant organization form. In this paper, we introduce more actual setting in which driver and carrier ownerships are both possible depending on several parameters. Thus analyzing the difference in parameters in Korea and U.S. qualitatively is meaningful in our model.

First, among other things, it is certain that strong economies of scale favor the carrier ownership because truck operation/maintenance and parking activity involve some feature of fixed input of production, which makes larger production units more cost efficient than owner operators. In addition, the extent of scale economy is confined by the size of the market. Thus $A$ rises with the increase in scale economy and market size. Kim and Ha (2003) has found significant economies of scale in Korean trucking industry. In addition, we can use total road transportation 
cost for a proxy of trucking market size. Lee and Seo (2004) reports that in 2002, the total road transportation cost in U.S. is about 460 billion dollars, and it is about 48 billion dollars in Korea, thus the U.S.. trucking market size is around 10 times that of Korea. This fact may raise the parameter value of $A$ in U.S., and serves as a clue for the huge difference between the owneroperator shares.

Second, there is an explanation why the productivity of common effort $\left(a_{1}\right)$ is larger in Korea than U.S. Note that the common efforts are such activities as vehicle maintenance, careful driving, and other non-driving service activities. We can see that these efforts are more valuable when road congestion is serious, and the unit cost of truck operation is higher. When road congestion is serious problem, there could be more chances of vehicle accidents, making proper maintenance and safe driving more valuable. When unit cost is higher, more common efforts are expended and more costs could be saved. With no data on the extent of road congestion, we can use the ratio of truck cargo transportation as a proxy since other things being equal, we can predict that higher truck cargo transportation implies higher road congestion. Lee and Seo (2004) provide such data. In 2002, the ratio of truck cargo transportation is $40.9 \%$ in U.S., and $88.1 \%$ in Korea. The unit cost is 0.2 dollar per ton-kilometer in U.S., and 0.7 dollar per ton-kilometer in Korea. These differences may indicate the difference in productivity of common efforts in U.S. and Korea, and could serve one possible explanation of larger common effort productivity.

Third, the specific effort is meaningful one only in driver ownership. An important specific effort is to find backhauls by a driver himself as discussed before. Here, $a_{2}$ is higher when hauls use trailers for which demands are bi-directional and there are lots of empty trucks; drivers can find backhauls for the truck other than the one their carrier (or dispatcher) wants them to take. If hauls use trailers for which demands are unidirectional and there are small numbers of empty trucks, there will be no need for the specific effort. One example of unidirectional demand is logging, which portion is extremely small in Korea. Furthermore, the ratio of empty backhaul vehicle is $49.1 \%$ in Korea, while it is around $20 \%$ in U.S. Thus above evidence could be provided as larger specific effort productivity in Korea.

Finally, the contractibility of common effort can be increased by the proper adoption of information technology. Let us first consider 'trip recorders', which monitor how drivers operate trucks, record when trucks are turned on and off, trucks' speed over time, and incidents of hard braking, etc. The introduction of this kind of IT will increase the contractibility of common effort since it raises the verifiability of efforts. In the mean time, IT such as 'TRS' (Trunked Radio System), which is a type of radio communications system between drivers and dispatchers, has no role in increasing the contractibility of common effort since the location of trucks is not verifiable. Thus it may be interesting whether the drivers adopted IT such as 'trip recorder' or 'TRS'. With no concrete data on the adoption rates, we can find the trend in the market from indirect evidence. The CVO (Commercial Vehicle Operations) system with the function of 'trip recorders' has been operating partly funded by the government. In 2005, the Board of Audit and Inspection (BAI) reviewed the adoption rate of trip recorders, and reported that less than $2 \%$ of total trucks were using the service. Meanwhile there is evidence that TRS users have been increasing by $40 \%$ 
annually since $2000 .^{9}$ Thus these can be served as evidence that IT adoption in Korean trucking industry is biased to the technology that cannot play much role in increasing the contractibility of common effort.

\section{Conclusion}

One of the distinguishable features in Korea and the U.S. trucking industries is the huge difference in the share of owner-operators. While it is around 10 15 percent in the U.S., 80 90\% of trucks are driven by drivers who operate their own truck in Korea. Previously, several reasons for the status quo of widespread existence of owner-operators in Korea are presented from the historical aspect. First, trucking business in Korea had been licensed, and most licensees were owner-operators rather than trucking companies. Second, after the license system was transformed into the registry system in 1999, a massive entry of owner operators into the trucking industry took place. Third, the situation was aggravated during the periods of IMF financial crisis, in which many unemployed tried to find an easy job, such as an owner-operator of truck.

In contrary, we examine theoretically what brings the difference in asset ownership structures between Korea and the U.S. trucking industry in this paper. Using an analytic framework we investigate what determines whether drivers own the trucks they operate, and how ownership patterns change as some environment changes. Furthermore the model introduces several parameters to affect drivers' decisions, of which movement is discussed and found to be consistent with the aforementioned characteristics.

The model explicitly considers drivers' decision on the truck ownership. Using a qualitative analysis, the model's prediction is consistent with the aforementioned characteristics. Korea has smaller market size, which reduces the extents of scale economy favoring carrier ownership. The marginal productivity of common effort - effort which is valuable both in carrier and driver ownership - may be larger since road congestion is serious and unit cost is larger in Korea. The marginal productivity of specific effort - effort which is valuable only in driver ownership - may be larger since hauls are bi-directional and empty vehicle are easy to find. IT adoption in Korea also is biased to the technology that cannot play much role in increasing the contractibility of common effort.

In addition to the model prediction and explanation, we could provide different policy implications with those previously raised to resolve the fragmented and less advanced characteristics of the domestic trucking industry. First, the large owner-operator share may be the outcome of rational choices of trucking industry's participants, not something resulted from bad system and intention. Second, if the view is correct, remedies for the market should be designed, given the vast existence of owner-operators. Altering the truck ownership in short period is almost impossible since it is the outcome of rational choice and we need huge changes on the truck industry's conditions to induce more carrier ownership. Third, it is the most important question

${ }^{9}$ This number is from the interview with a person in domestic TRS service operator, 'KT Power Tel.' 
how to improve the productivity of owner-operators and to preserve the competitive nature of the market. Temporary oversupply may lead to hard times for some drivers, but exit barrier should be lower for the long run rational choice of the market participants.

\section{Acknowledgement}

The authors have benefited from the comments of anonymous referees and gratefully acknowledge the financial support of Inha University.

\section{References}

BAI. 2005. The audit report on logistic market. The Board of Audit and Inspection. Seoul, Korea.

Chung, S. and D. Lim. 2006. A study on an improvement plan for statistics and a survey system of the trucking industry. The Korea Transport Institute.

Clemons, E. K. and P. R. Kleindorfer. 1992. An economic analysis of interorganizational information systems. Decision Support Systems. 8(5): 431-446.

Grossman, S. F. and O. Hart. 1986. The costs and benefits of ownership: a theory of vertical and lateral integration. Journal of Political Economy. 94(4): 691-719.

Han, K., R. J. Kauffman, and B. R. Nault. 2004. Information exploitation and interorganizational systems ownership. Journal of Management Information Systems. 21(2): 109-135.

Hart, O. and J. Moore. 1990. Property rights and the nature of the firm. Journal of Political Economy. 98(6): 1119-1158.

Hart, O. 1995. Firms contracts and financialsStructure. Oxford University Press, Oxford, UK.

Hubbard, T. N. 2000. The demand for monitoring technologies: the case of trucking. Quarterly Journal of Economics. 115(2): 533- 60.

Hubbard, T. N. 2003. Information, decisions, and productivity: on-board computers and capacity utilization in trucking. American Economic Review. 93(4): 1328-1353.

Kim, T. S. and H. K. Ha. 2003. The effects of deregulation policy in the trucking industry: focusing in deregulation policy in the 1990s. Journal of Logistics Studies. 11(1): 41-58.

Klein, B., R. Crawford, and A. Alchian. 1978. Vertical integration, appropriable rents, and the competitive contracting process. Journal of Law and Economics. 21(October): 297-326.

Lee, J. and S. Seo. 2004. Strategies to decrease national logistics costs for improving national competitiveness. The Korea Transport Institute.

Lee. J. 2008. A study on the fuel subsidies of the freight transport industry. Journal of Korean Economic Studies. 20(1): 135-163.

Milgrom, P. and J. Roberts. 1992. Economics, organization, and management. Englewood Cliffs, 
NJ: Prentice-Hall.

Williamson, O.E. 1985. The economic institutions of capitalism. New York: Free Press. 